Copyright (C) 2004 IEEE. Reprinted from

IEEE Transactions on Power Systems, 2004; 19 (1):463-472

This material is posted here with permission of the IEEE. Such permission of the IEEE does not in any way imply IEEE endorsement of any of the University of Adelaide's products or services. Internal or personal use of this material is permitted. However, permission to reprint/republish this material for advertising or promotional purposes or for creating new collective works for resale or redistribution must be obtained from the IEEE by writing to pubs-permissions@ieee.org.

By choosing to view this document, you agree to all provisions of the copyright laws protecting it. 


\title{
Reconciliation of Methods of Compensation for PSSs in Multimachine Systems
}

\author{
Michael J. Gibbard, Fellow, IEEE, and David J. Vowles, Member, IEEE
}

\begin{abstract}
Several methods for the design of compensation for power system stabilizers (PSSs) are used in practice. The object of this paper is to reconcile the methods and explore their relative advantages and disadvantages. Three methods are investigated: the GEP and the P-Vr frequency response approaches, and the method of residues. It is shown the phase response of a modified GEP transfer function (TF) agrees closely with that of the P-Vr TF, thus providing the basis for the design of a robust PSS. Residues yield only a limited number of phase angles that can be used with confidence for design purposes and are consistent with the $\mathrm{P}-\mathrm{Vr}$ phase response. The remaining residues for rotor modes are affected by variability of participation factor angles and interactions from other machines. Unlike other methods, the P-Vr approach yields magnitude and phase information that simplifies the synthesis of the PSS TF and yields a robust stabilizer.
\end{abstract}

Index Terms-Power system dynamic stability, power system stabilizers.

\section{INTRODUCTION}

$\mathbf{T}$ HE paper by de Mello and Concordia in 1969 [1] provided the basis for the design of many power system stabilizers (PSSs) in operation today. Based on the concept of damping and synchronizing torques developed on the shaft of a generator, a technique was presented for tuning a PSS for a single-machine infinite-bus system. In this approach, the PSS transfer function is designed to provide phase-compensation of the transfer function between the voltage reference input to the AVR and the electrical torque developed on the shaft of the generator. The use of a single-machine model results in a single mode of rotor oscillation, however, in practice, a generator may participate significantly in certain interarea, local area, and intrastation modes with frequencies of oscillation ranging from 1.5 to $12 \mathrm{rad} / \mathrm{s}$.

Larsen and Swann described in 1981 a practical procedure for tuning PSSs based on the design approach of de Mello and Concordia [2]. The transfer function (TF) between the voltage reference input to the AVR and the electrical torque developed on the shaft is called generator, excitation system and power system [GEP(s)]. Because the GEP(s) is proportional to the TF from voltage reference $\left(V_{r}\right)$ to terminal voltage $\left(V_{r}\right)$, the frequency response $V_{t}(j \omega) / V_{r}(j \omega)$ is measured instead. Compensation for the phase response over an appropriate frequency range is used in determining the PSS TF. A further test is performed to determine the gain setting of the PSS. This test consists of raising

Manuscript received May 23, 2003. This work was supported by a number of Australian transmission network service providers.

The authors are with the School of Electrical and Electronic Engineering, The University of Adelaide, Adelaide 5005, South Australia (e-mail: michael.gibbard@adelaide.edu.au; david.vowles@adelaide.edu.au).

Digital Object Identifier 10.1109/TPWRS.2003.820689 the gain until the onset of instability is observed; the PSS gain is then set to $1 / 3$ rd of this value. A further development of the GEP approach is reported in [3].

Using the damping torque concepts developed for the single machine system [1], [4], a procedure for the design of PSSs in multimachine systems was proposed by Gibbard in 1988 [5]. It has since been shown that these design concepts for the singlemachine case can be extended to derive a single, centralized PSS for a multimachine system [6]. With some simplifying assumptions, the analysis provides a formal, theoretical basis for the design described in [7] of practical, decentralized PSSs in multimachine systems in which each machine may encounter the range of rotor modes mentioned above. As in [4], this approach employs the so-called $\mathrm{P}-\mathrm{Vr} \mathrm{TF}$ which is defined as the transfer function from the voltage reference (Vr) input to the electrical power $(\mathrm{P})$ i.e., torque, output of the generator when the shaft dynamics of all machines are disabled (disabling is equivalent to setting the inertia constants of all machines to infinity). The TFs of the multimachine PSSs are of the form $\left[k_{j} \cdot G_{j}(s)\right]$, a structure commonly used in the industry. In the $\mathrm{P}-\mathrm{Vr}$ design procedure, the $\operatorname{TF} G_{j}(s)$ is designed to compensate for both the magnitude and phase shift introduced by the P-Vr TF for machine $j$; this results in the left shift of the relevant modes. However, the extent of the left-shift is determined primarily by the setting of the gain $k_{j}$, which is also the value of the damping torque coefficient defined in [5]. This procedure is used in the Australian Electricity Supply Industry (see Appendix A).

It was shown in [6] that fixed-parameter PSSs based on the $\mathrm{P}-\mathrm{Vr}$ TFs provide satisfactory damping of the rotor modes over a wide range of operating conditions. The robust nature of the design is due to the more-or-less invariant nature of the $\mathrm{P}-\mathrm{Vr}$ characteristic of individual generators; this was confirmed in a theoretical analysis of Lam [8]. Lam showed that P-Vr TF is determined primarily by the excitation system and the electrical circuits of the generator. An example of the more-or-less invariant characteristic of the P-Vr TF is shown in Fig. 1 for a generator in an actual large system covering some 120 operating conditions of which 35 are normal conditions and the remainder line-outage conditions, etc.

While stabilizer designers have their own preferred procedures, the paper's aim is to reconcile the methods - which complement each other-and assess their relative merits.

\section{RELATIONSHIP OF RESIDUES TO P-Vr TFS}

Consider a generator or flexible ac transmission (FACTS) device stabilizer with a TF of the form $S_{j}(s)=k_{j} \cdot G_{j}(s)$ between the $m^{\text {th }}$ output (the local stabilizing signal) and the $j^{\text {th }}$ input (at 

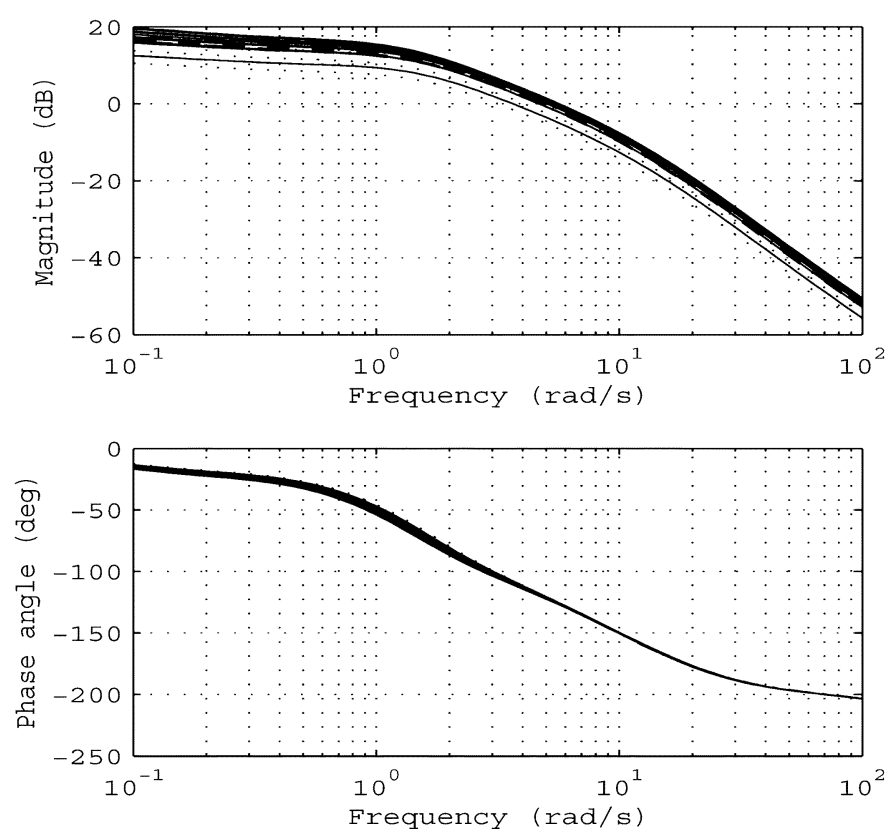

Fig. 1. P-Vr characteristics of a generator in a large system for a very wide range of normal and outage conditions.

the summing junction of the generator or FACTS device). $G_{j}(s)$ includes the compensating TFs as well as washout block(s) and possibly low-pass filter(s). It is shown in [9] that if the stator resistance is assumed negligible, the shift in the rotor mode of oscillation $\lambda_{h}$ due to an increment in gain $\Delta k_{j}$ on the stabilizer $j$ is

$$
\begin{gathered}
\Delta \lambda_{h} \approx \xi_{m j}\left(\lambda_{h}\right) G_{j}\left(\lambda_{h}\right) \Delta k_{j}, \\
\text { if }\left\|\xi_{m j}\left(\lambda_{h}\right)\left(\frac{\partial S_{j}\left(\lambda_{h}\right)}{\partial \lambda_{h}}\right)\right\| \ll 1, \\
\text { where } \xi_{m j}\left(\lambda_{h}\right)=-\sum_{i=1}^{n}\left\{\frac{p_{i h}}{M_{i}} \frac{\mathbf{c}_{m *} \mathbf{u}_{* h}}{u_{i h}} H_{P i j}\left(\lambda_{h}\right)\right\} .
\end{gathered}
$$

In (2), $M_{i}$ is twice the inertia constant of machine $i ; p_{i h}$ is the participation factor of the speed state of machine $i$ in the $h$ th mode; $\mathbf{u}_{* h}$ is the right eigenvector; $\mathbf{c}_{m *}$ is the row of the system C matrix associated with the $m$ th output; $H_{P i j}\left(\lambda_{h}\right)$ is the $\mathrm{P}-\mathrm{Vr}$ TF between the voltage reference input of device $j$ and the electrical power output of generator $i$, evaluated at the complex frequency $\lambda_{h}$ with the shaft dynamics on all machines disabled.

It is also shown in [9] that $\xi_{m j}\left(\lambda_{h}\right)$ in (2) is the residue for the rotor mode $\lambda_{h}$ evaluated for the TF between the voltage reference input $\Delta V_{r j}$ to the $j^{\text {th }}$ generator and output $m$ (i.e., $\left.r_{m j}^{h}=\xi_{m j}\left(\lambda_{h}\right)\right)$. For the case of a speed-PSS on unit $j$, the output is rotor speed perturbations, $\Delta \omega_{r j}$; (1) and (2) can be written as

$$
\begin{aligned}
\Delta \lambda_{h} & \approx r_{j j}^{h} G_{j}\left(\lambda_{h}\right) \Delta k_{j} \\
\text { and } r_{j j}^{h} & =\left[-\frac{p_{j h}}{M_{j}} H_{P j j}\left(\lambda_{h}\right)-\sum_{i=1 \neq j}^{n}\left\{\frac{p_{i h}}{M_{i}} \frac{u_{j h}}{u_{i h}} H_{P i j}\left(\lambda_{h}\right)\right\}\right],
\end{aligned}
$$

consisting of the "self" (1st) term and "interaction" terms, that is

$$
\approx\left[-\frac{p_{j h}}{M_{j}} H_{P j j}\left(\lambda_{h}\right)-\sum_{i=1 \neq j}^{n}\left\{\frac{p_{i h}}{M_{i}} \frac{u_{j}}{u_{i}} H_{P i j}\left(\lambda_{h}\right)\right\}\right] \cdot G_{j}\left(\lambda_{h}\right) \Delta k_{j} .
$$

The form of (3) for the mode shift is well known [10]. The expression (5) formed the basis in [11] for the analysis of interactions between PSSs in multimachine systems; these results were also reported in [12].

\section{PSS DESIGNS BASED ON GEP, P-Vr AND RESIDUES}

\section{A. PSS Design Based on the GEP Method}

The design of a PSS in a multimachine system employs the method of Larson and Swan. In this method, the compensation angle for the PSS TF is the negative of the phase shift of the measured or calculated frequency response $V_{t}(j \omega) / V_{r}(j \omega)$. From this result, a compensating TF is synthesized for the PSS; the gain of the PSS is set as described in Section I.

\section{B. PSS Design Based on the Generator P-Vr Characteristic}

In the design of the PSS, details of which are given in Appendix A, the PSS TF $G_{j}(j \omega)$ is designed to compensate for its $\mathrm{P}-\mathrm{Vr}$ characteristic $H_{j j}(j \omega)$, that is

$$
G_{j}(j \omega)=\frac{1}{H_{P j j}(j \omega)}
$$

over the range of rotor modes [5]. Equation (5) then reduces to

$\Delta \lambda_{h} \approx-\frac{p_{j h}}{M_{j}} \cdot \Delta k_{j}-\sum_{i=1 \neq j}^{n}\left\{\frac{p_{i h}}{M_{i}} \frac{u_{j h}}{u_{i h}} H_{P i j}\left(\lambda_{h}\right)\right\} G_{j}\left(\lambda_{h}\right) \Delta k_{j}$.

In the first term $p_{j h}$ is generally close to a real value if the speed state of generator $j$ participates significantly in mode $\lambda_{h}$. Consequently, the first term produces a direct left shift in the $s$-plane and is the contribution to damping by the PSS on machine $j$; such damping is either enhanced or degraded by interactions with other generators (the second term). Such information is not available through the conventional calculation of the residue $r_{j j}^{h}$. Equation (4) allows the contributions to the residue from each of the $n$ generator paths between $\Delta V_{r j}$ as input and $\Delta \omega_{r j}$ as output to be calculated.

\section{PSS Design Based on Residues}

The use of residues has been employed for the design of generator PSSs [12, Appendix A]. The associated mode shift is given by (3). In order to shift the mode directly to the left in the $s$-plane, the design technique based on residues requires that for each of the rotor modes of concern, the phase of PSS TF $G_{j}(j \omega)$ is

$$
\arg \left\{G_{\operatorname{Res}_{j}}\left(\lambda_{h}\right)\right\}=180^{\circ}-\arg \left\{r_{j j}^{h}\right\}
$$

where $G_{\operatorname{Res}_{j}}(s)$ is the TF of the compensator $G_{j}(s)$ designed using the residue method. It will be shown that the shortcoming 
of this approach is that it is difficult to determine the parameters of a TF $G_{\operatorname{Res}_{j}}(s) \cdot k_{R j}$ that

- satisfies the required phase shifts over the range of localarea, interarea, and intermachine rotor modes;

- are robust over a wide range of operating conditions. Moreover, there is no basis for determining the PSS gain $k_{R j}$.

\section{Comparison of Residue and P-Vr TF Methods}

Consider the design of the PSS TF based of the P-Vr method. In order that the machine and PSS $j$ contribute to a direct left shift of mode $\lambda_{h}$, the compensation angle required for that mode is from (6)

$$
\arg \left\{G_{P S S_{-} j}\left(\lambda_{h}\right)\right\}=-\arg \left\{H_{P j j}\left(\lambda_{h}\right)\right\}
$$

where $G_{P S S_{-} j}(s)$ is the compensation provided by PSS TF.

Furthermore, let us assume (5) can be written as

$$
\Delta \lambda_{h} \approx\left[-\frac{p_{j h}}{M_{j}} H_{P j j}\left(\lambda_{h}\right) \cdot E_{j h}\right] \cdot G_{j}\left(\lambda_{h}\right) \Delta k_{j}
$$

where the participation factor $p_{j h}$ is complex, and the complex factor $E_{j h} \angle \varepsilon_{j h}$ accounts for the unknown effects of interactions by other generators on the "self" term. In order that machine and PSS $j$ contribute to a direct left shift of mode $\lambda_{h}$, a more general form for the compensation angle required for the mode is

$$
\arg \left\{G_{P S S_{-} j}\left(\lambda_{h}\right)\right\}=-\arg \left\{p_{j h}\right\}-\arg \left\{H_{P j j}\left(\lambda_{h}\right)\right\}-\varepsilon_{j h} .
$$

Assume: i) for the rotor modes in which machine $j$ participates significantly, $p_{j h}$ is nearly real, and ii) the effects of interactions are negligible. The compensation angle required for a given mode then reduces from (10) to

$$
\arg \left\{G_{P S S_{-j}}\left(\lambda_{h}\right)\right\} \approx-\arg \left\{H_{P j j}\left(\lambda_{h}\right)\right\} .
$$

In order that PSS $j$ contributes to a direct left shift of mode $\lambda_{h}$, we conclude from (3), (10), and (11) that the compensation angles required by the residue and $\mathrm{P}-\mathrm{Vr}$ methods are related by

$$
\begin{aligned}
\arg \left\{G_{\text {Res }_{-} j}\left(\lambda_{h}\right)\right\} & =\arg \left\{G_{P S S_{-} j}\left(\lambda_{h}\right)\right\} \\
& =-\arg \left\{p_{j h}\right\}-\arg \left\{H_{P j j}\left(\lambda_{h}\right)\right\}-\varepsilon_{j h}
\end{aligned}
$$

Substitution of (13b) into (8), reveals that the phase angle of the residue and the $\mathrm{P}-\mathrm{Vr}$ characteristic at the rotor mode $\lambda_{h}$ are related by

$$
\arg \left\{H_{P j j}\left(\lambda_{h}\right)\right\} \approx \arg \left\{r_{j j}^{h}\right\}-180^{\circ} .
$$

It should be noted that ideal, accurate phase compensation is provided by the residue angles and includes the markedly variable effects of interactions. The significance of these effects is examined as part of the comparison of the methods.

\section{COMPARISON OF COMPENSATION Methods}

In order to compare the three methods of compensation for PSSs in multimachine systems, a case study on a practical system of some 120 generators having a number of interarea modes will be examined. For the purposes of these studies, it is assumed that all PSSs for which compensation is to be determined employ rotor speed perturbations as the stabilizing signal. In the following analysis, two cases are considered.

i) All PSSs are out of service and stabilizers on SVCs and other FACTS devices are disabled. (When shaft dynamics are disabled for calculation of the P-Vr TF, speed-PSSs are inherently deactivated and calculations are simplified.)

ii) All PSSs and other stabilizers are in service except for the machine of interest-and possibly other units in the same station. [It will be confirmed that results obtained for case ii) are consistent with those derived in i)].

\section{COMPARISON OF GEP AND P-Vr CHARACTERISTICS}

The use of the phase response of the conventional GEP TF, as well as that of the magnitude and phase responses of the $\mathrm{P}-\mathrm{Vr}$ characteristic, in the design of the PSS TF were explained in Section III.

For selected generators, the frequency responses for the conventional GEP TFs $\left[V_{t}(j \omega) / V_{r}(j \omega)\right]$ and the P-Vr TF $\left[P(j \omega) / V_{r}(j \omega)\right.$ with all rotor shaft dynamics disabled] are shown in Fig. 2. The GEPs for two cases are provided, all PSSs out-of-service and all PSSs in-service except on the units concerned. Due to certain local-area and intrastation modes in the range $8-12 \mathrm{rad} / \mathrm{s}$ being lightly damped, resonances are displayed in the GEP frequency responses. Whether PSSs are in- or out-of service does not affect the underlying form of the response. If the GEP TF is calculated with all shaft dynamics disabled (GEPSDD), these resonances are eliminated and its phase response generally agrees closely with that of the $\mathrm{P}-\mathrm{Vr}$ TF, as seen in Fig. 3. From a comparison of the latter two figures, the following observations are offered.

- As is to be expected, the magnitude responses of the conventional GEP and the P-Vr TFs differ. (The gain of the GEP TF $V_{t}(j \omega) / V_{r}(j \omega)$ tends to unity at low frequencies.)

- The conventional GEP phase response may be "distorted" by a number of resonances (which should be attenuated markedly by the damping introduced by properly-designed PSSs). Such phase responses and the lack of appropriate magnitude information complicate the synthesis of the PSS TF. (It is usually a matter of juggling a number of lead-lag networks to obtain the desired lead compensation over the range of modal frequencies.)

- The magnitude responses for the P-Vr and the GEPSDD TFs differ by a constant gain value. There is generally good agreement between the $\mathrm{P}-\mathrm{Vr}$ and GEPSDD phase responses. These observations can be explained from a consideration of the single-machine system (see Appendix B). From a comparison of Figs. 2 and 3, the GEPSDD phase response is seen to provide a good "smoothed" representation of that of the GEP.

In conclusion:

- Field-measured GEP responses may be adulterated by resonances due to lightly damped local or intrastation modes. 

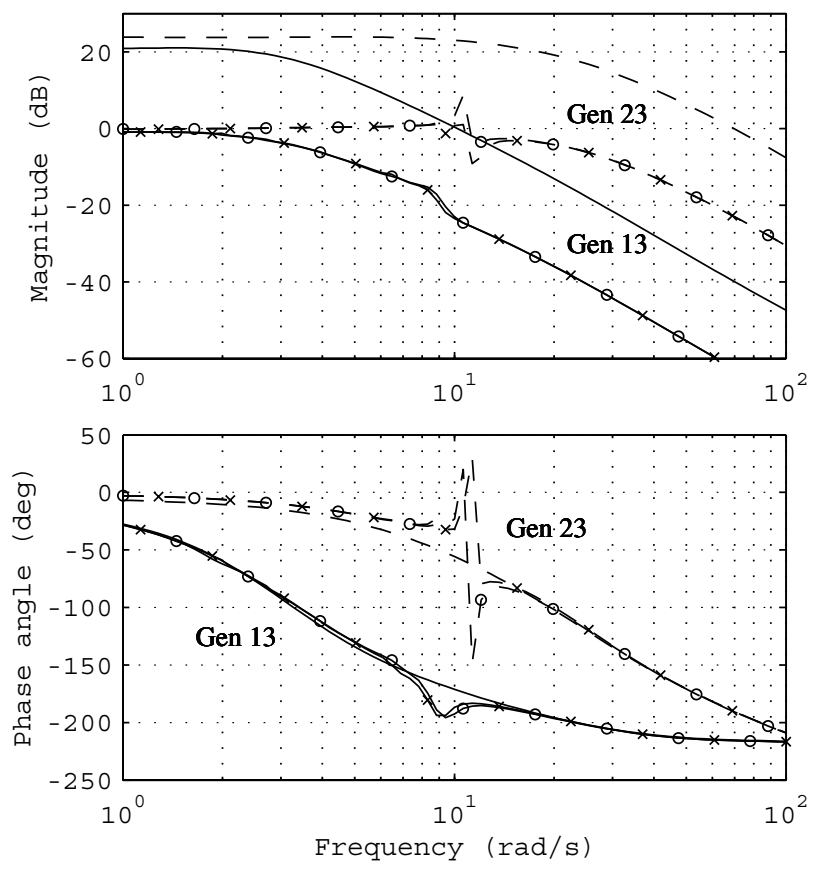

GEPs. PSSs off $\mathrm{x}--\mathrm{x}$; PSSs on $\mathrm{o--}-\mathrm{o}$

PVrGen $13 \quad-\quad$ PVr Gen 23

Fig. 2. Gens. \#13 and \#23: Frequency responses for P-Vr and GEPs with PSS off/on on all other units. (100-MVA base).

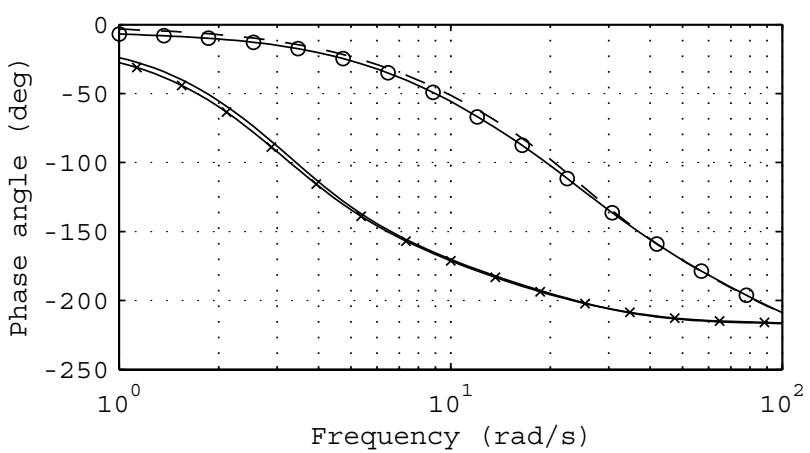

$\times$ PVr Gen $13 \quad 0 \quad 0 P$ Vr Gen 23

GEPSDD Gen $13 \quad-\quad$ GEPSDD Gen 23

Fig. 3. Gens. \#13 and \#23. Frequency responses for P-Vr and GEP (shaft dynamics disabled). (100-MVA base).

- By eliminating the resonances associated with the rotor modes of the conventional GEP TFs, the phase responses of the GEPSDD TFs provide a sounder basis for the determination of phase compensation required in PSS TFs.

- Because both the magnitude and phase of the P-Vr TF can be employed in establishing the magnitude and phase compensation required in the PSS TF, the P-Vr TF provides additional valuable information for its synthesis.

- Field-measured GEPs can assist in the validation of the small-signal system models used in simulation-based PSS tuning methods.
TABLE I

GENERATOR 55 (ONE OF TWO IN THE STATION) Residues OF Rotor MOdes IN TF $\Delta \omega / \Delta V_{r}$ (SEE Fig. 4)

\begin{tabular}{l|l|l|l|l}
\hline $\begin{array}{l}\text { Rank- } \\
\text { ing }\end{array}$ & $\begin{array}{c}\text { Rotor Mode } \lambda_{\mathrm{h}} \\
\text { \& Type }\end{array}$ & $\begin{array}{c}\text { PF (units) } \\
/ \text { Ranking }\end{array}$ & $\begin{array}{c}\text { Residue } \\
\text { (units) }\end{array}$ & $\angle \beta_{j j}^{h^{\circ}}$ \\
\hline 1 & $-0.48+\mathrm{j} 5.17$ LA & $460 \angle 0^{\circ} / 1$ & $12 \angle 123^{\circ}$ & $-57^{\circ}$ \\
\hline 2 & $-0.02+\mathrm{j} 2.80$ IA & $30 \angle-6^{\circ} / 1$ & $0.5 \angle 126^{\circ}$ & $-54^{\circ}$ \\
\hline 3 & $-0.02+\mathrm{j} 2.02$ IA & $16 \angle-7^{\circ} / 5$ & $0.3 \angle 125^{\circ}$ & $-55^{\circ}$ \\
\hline 4 & $+0.01+\mathrm{j} 4.05$ IA & $6 \angle-25^{\circ} />40$ & $0.1 \angle 101^{\circ}$ & $-79^{\circ}$ \\
\hline
\end{tabular}

Ranking: In order of decreasing magnitude of the residue of rotor modes $\lambda_{h}$ only.

Mode Type: IA: interarea; LA: local-area; IS: intrastation.

PF: Participation factor. PF Ranking: by magnitude of the generator's speed state in the mode $\lambda_{h}$.

Residue and PF values in units 1 unit $=10^{-3}$.

TABLE II

GENERATOR 40 (ONE OF Two IN THE STATION) RESIDUES OF ROTOR MODES IN TF $\Delta \omega / \Delta V_{r e f}$ (SEE FIG. 5)

\begin{tabular}{|c|c|c|c|c|}
\hline $\begin{array}{l}\text { Rank- } \\
\text { ing }\end{array}$ & $\begin{array}{c}\text { Rotor Mode } \\
\text { \& Type }\end{array}$ & $\begin{array}{l}\text { PF (units) } \\
\text { / Ranking }\end{array}$ & $\begin{array}{c}\text { Residue } \\
\text { (units) }\end{array}$ & $\angle \beta_{j j}^{h}$ \\
\hline 1 & $-0.64+\mathrm{j} 8.93$ IS & $260 \angle 1^{\circ} / 1$ & $66 \angle 63^{\circ}$ & $-117^{\circ}$ \\
\hline 2 & $-0.23+j 7.16 \mathrm{LA}$ & $145 \angle 4^{\circ} / 1$ & $37 \angle 93^{\circ}$ & $-87^{\circ}$ \\
\hline 3 & $-0.88+j 9.19 \mathrm{LA}$ & $63 \angle-5^{\circ} / 9$ & $18 \angle 65^{\circ}$ & $-116^{\circ}$ \\
\hline 4 & $-0.02+j 2.80$ IA & $17 \angle 8^{\circ} / 9$ & $3 \angle 158^{\circ}$ & $-22^{\circ}$ \\
\hline 5 & $-0.02+j 2.02$ IA & $12 \angle 2^{\circ} / 31$ & $2 \angle 166^{\circ}$ & $-14^{\circ}$ \\
\hline 6 & $-0.78+j 7.59$ LA & $5 \angle-73^{\circ} / 33$ & $2 \angle 13^{\circ}$ & $-167^{\circ}$ \\
\hline 7 & $-0.48+\mathrm{j} 5.17$ LA & $5 \angle 22^{\circ} / 10$ & $1 \angle 140^{\circ}$ & $-40^{\circ}$ \\
\hline
\end{tabular}

1 unit $=10^{-3}$. See Table I for a definition of terms.

\section{COMPARISON OF PHASE COMPENSATION PROVIDED BY THE P-Vr TF AND RESIDUES}

\section{A. All PSSs and Other Stabilizers Out of Service}

Typical phase responses of the P-Vr TF, $H_{P j j}(j \omega)$, are given in Figs. 1-3. For calculation of the P-Vr TF, the speed-PSSs are inherently out of service. As explained in Section II, the residue of interest is that for the mode $\lambda_{h}$ evaluated for the TF $\Delta \omega_{r j}\left(\lambda_{h}\right) / \Delta V_{r j}\left(\lambda_{h}\right)$ of the $j$ th generator.

Since (8) and (9) reveal the phase compensation required by the residue and P-Vr methods, a comparison between the phase compensation derived from the residue angle $\arg \left\{r_{j j}^{h}\right\}$, and that from the P-Vr TF can be assessed by plotting $180^{\circ}-\arg \left\{r_{j j}^{h}\right\}$ on the phase response $-\arg \left\{H_{P j j}(j \omega)\right\}$ of the P-Vr TF. However, since the phase responses of $+\arg \left\{H_{P j j}(j \omega)\right\}$, have been employed earlier, it is convenient to plot the angle

$$
\beta_{j j}^{h}=\arg \left\{r_{j j}^{h}\right\}-180^{\circ}
$$

instead, on the latter P-Vr phase responses. A selection of such phase plots is shown in Figs. 4-6; these plots for four generators are representative of four different types of behavior found in the residues. On the $\mathrm{P}-\mathrm{Vr}$ phase plot of each generator is shown the angle $\beta_{j j}^{h}$ for the modal frequency of rotor oscillations $\lambda_{h}$ (these angle values are called "points" on the plots in the following text). In each of Tables I-IV for selected generators, the angles $\beta_{j j}^{h}$ are ranked in descending order of the magnitude of the residue $r_{j j}^{h}$.

Consider Fig. 4 and Table I for generator \#55.

Angle points $\beta_{j j}^{h}$ ranked 1, 2, and 3 in Fig. 4 agree closely with the phase plot of the P-Vr TF. Note that the rotor modes 
TABLE III

GENERATOR 13 (More Than Four in the Station) Residues of Rotor MODES IN TF $\Delta \omega / \Delta V_{r e f}$ (SEE FIG. 6)

\begin{tabular}{l|l|l|l|l}
\hline $\begin{array}{l}\text { Rank- } \\
\text { ing }\end{array}$ & $\begin{array}{c}\text { Rotor Mode } \\
\text { \& Type }\end{array}$ & $\begin{array}{c}\text { PF (units) / } \\
\text { Ranking \# }\end{array}$ & $\begin{array}{c}\text { Residue } \\
\text { (units) }\end{array}$ & $\angle \beta_{j j}^{h}$ \\
\hline 1 & $-0.84+\mathrm{j} 8.50$ IS & $278 \angle-18^{\circ} / 3$ & $20 \angle-14^{\circ}$ & $-194^{\circ}$ \\
\hline 2 & $-0.84+\mathrm{j} 8.46$ IS & $167 \angle 47^{\circ} / 3$ & $12 \angle-52^{\circ}$ & $-128^{\circ}$ \\
\hline 3 & $-0.64+\mathrm{j} 7.89$ IS & $49 \angle-6^{\circ} / 9$ & $4 \angle 3^{\circ}$ & $-177^{\circ}$ \\
\hline 4 & $-0.87+\mathrm{j} 8.43$ IS & $37 \angle-54^{\circ} / 8$ & $3 \angle-49^{\circ}$ & $-229^{\circ}$ \\
\hline 5 & $-0.02+\mathrm{j} 2.02$ IA & $15 \angle 1^{\circ} / 17$ & $2 \angle 140^{\circ}$ & $-40^{\circ}$ \\
\hline 6 & $-0.30+\mathrm{j} 6.51$ LA & $12 \angle 24^{\circ} / 27$ & $1 \angle 53^{\circ}$ & $-127^{\circ}$ \\
\hline 7 & $-0.56+\mathrm{j} 7.14$ LA & $11 \angle-27^{\circ} / 27$ & $1 \angle-9^{\circ}$ & $-189^{\circ}$ \\
\hline 8 & $-0.37+\mathrm{j} 8.95$ LA & $11 \angle-3^{\circ} / 27$ & $1 \angle-3^{\circ}$ & $-183^{\circ} \#$ \\
\hline 9 & $-0.56+\mathrm{j} 5.63$ LA & $6 \angle 9^{\circ} / 18$ & $0.7 \angle 44^{\circ}$ & $-136^{\circ}$ \\
\hline 10 & $-0.02+\mathrm{j} 2.80$ IA & $6 \angle 1^{\circ} />40$ & $0.7 \angle 113^{\circ}$ & $-67^{\circ}$ \\
\hline
\end{tabular}

1 unit $=10^{-3}$. See Table I for definition of terms. \# indicates value not plotted on figure.

TABLE IV

GENERATOR 79 (ONE OF Two IN THE STATION) RESIDUES OF ROTOR MODES IN TF $\Delta \omega / \Delta V_{\text {ref }}$ (SEE FIG. 6)

\begin{tabular}{l|l|l|l|l}
\hline $\begin{array}{l}\text { Rank- } \\
\text { ing }\end{array}$ & $\begin{array}{c}\text { Rotor Mode } \\
\text { \& Type }\end{array}$ & $\begin{array}{c}\text { PF (units) } \\
/ \text { Ranking }\end{array}$ & $\begin{array}{c}\text { Residue } \\
\text { (units) }\end{array}$ & $\angle \beta_{j j}^{h}$ \\
\hline 1 & $-0.86+\mathrm{j} 10.3$ IS & $233 \angle-14^{\circ} / 3$ & $105 \angle 76^{\circ}$ & $-104^{\circ}$ \\
\hline 2 & $-1.05+\mathrm{j} 10.4$ LA & $188 \angle-3^{\circ} / 1$ & $94 \angle 89^{\circ}$ & $-91^{\circ}$ \\
\hline 3 & $-1.08+\mathrm{j} 9.52$ LA & $44 \angle 33^{\circ} / 9$ & $20 \angle 141^{\circ}$ & $-39^{\circ}$ \\
\hline 4 & $-0.80+\mathrm{j} 9.95$ LA & $17 \angle 42^{\circ} / 5$ & $8 \angle 145^{\circ}$ & $-35^{\circ}$ \\
\hline 5 & $-1.38+\mathrm{j} 10.0$ LA & $13 \angle 62^{\circ} / 20$ & $7 \angle 176^{\circ}$ & $-4^{\circ}$ \\
\hline 6 & $-0.59+\mathrm{j} 8.52$ LA & $8 \angle 33^{\circ} / 20$ & $4 \angle 135^{\circ}$ & $-45^{\circ}$ \\
\hline 7 & $+0.01+\mathrm{j} 4.05$ IA & $13 \angle 6^{\circ} / 3$ & $4 \angle 172^{\circ}$ & $-8^{\circ}$ \\
\hline
\end{tabular}

1 unit $=10^{-3}$. See Table I for a definition of terms.

associated with points 1 and 2 also possess for the respective rotor modes the largest (nearly real) participation factors.

As is the case for point 2 , points 3 and 4 correspond to interarea modes but are lower ranked in their associated participation factors (point 4 in particular).

In Fig. 5 for generator \#40, there is close agreement between points ranked 1,2, and 3 with the phase plot of the P-Vr TF. Table II reveals that the rotor modes associated with points 1 and 2 also possess the largest (nearly real) participation factors as well as the largest residues for the respective modes. The remaining points, 4-7, diverge from the $\mathrm{P}-\mathrm{Vr}$ response more significantly. Note, however, that in relative terms, the magnitudes of both their participation factors and residues are much smaller than those in points 1-3.

In Fig. 6 for generator \#13, there is a greater scatter of angle points $\beta_{j j}^{h}$ about the P-Vr phase plot, particularly for the intrastation and local-area modes. As there are more than four machines in the station, there are four intrastation modes with the largest residues [i.e., points 1-4 (see Table III)]. Note that their participation factors are ranked three or lower and, for points 2 and 4 , in particular, the angles of the participation factors deviate significantly from zero. The last observation will be considered again in part B. For points $5-10$, the magnitudes of both their participation factors and residues are less than $10 \%$ of those for the largest value (point 1).

For generator \#79 in Fig. 6 there is also a scatter of angle points $\beta_{j j}^{h}$ about the $\mathrm{P}-\mathrm{Vr}$ phase response, those ranked 1 and 2 in Table IV lying closest to the phase response. As before, the greatest deviations from the phase response are for those points

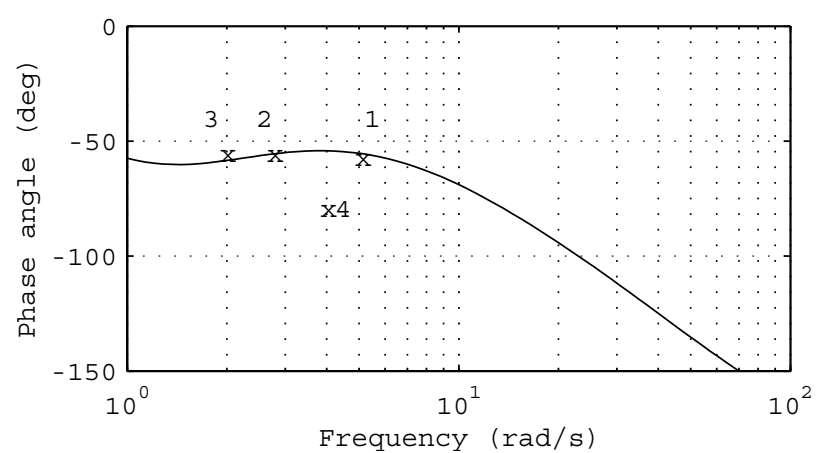

Fig. 4. Gen. 55. Angle $\beta(\mathrm{x})$, residue angle- $180^{\circ}$, plotted on $\mathrm{P}-\mathrm{Vr}$ phase response and ranked in order of residues magnitudes.

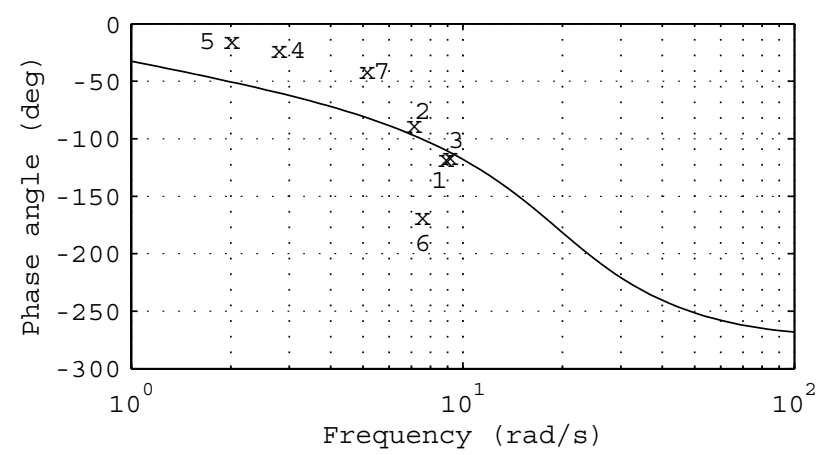

Fig. 5. Gen. 40. Angle $\beta(\mathrm{x})$, residue angle $-180^{\circ}$, plotted on $\mathrm{P}-\mathrm{Vr}$ phase response and ranked in order of residues magnitudes.

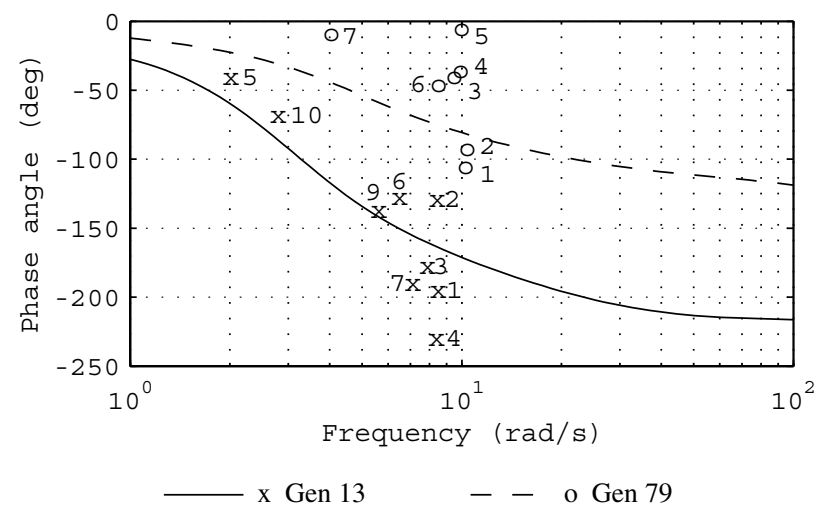

Fig. 6. Gen. 13 and 79. Angle $\beta(\mathrm{x} / \mathrm{o})$, residue angle- $180^{\circ}$, plotted on $\mathrm{P}-\mathrm{Vr}$ phase response; ranked in order of magnitude of residues.

for which the magnitudes of both their participation factors and residues are less than $10 \%$ of that for largest value (point 1 ), and/or the participation factors are complex.

Observations: Three categories are defined as follows.

Category

1: $\quad$ The angle points agree closely with the $\mathrm{P}-\mathrm{Vr}$ phase response for those generators whose participation factor in its speed state for the rotor mode $\lambda_{h}$ is ranked the largest. This is typically the case in which the machine swings against the second machine in the station, or the machine-and perhaps a second machine in the station-swing against the rest of the system. This applies to the highest 
ranked residues for generators 55 and 40 (Figs. 4 and 5, Tables I and II, respectively).

Category

2

Otherwise, there is generally a scatter of the angle points about the $\mathrm{P}-\mathrm{Vr}$ phase response of a given generator. This is usually the case when, for the rotor mode of interest, the machine is one of a number of-or of many-machines participating in the mode. Consequently, its participation factor is ranked lower. This applies to the lower ranked residues for generators 40,13 , and 79 .

Category

3:

In the second of the above categories, the angle points $\beta_{j j}^{h}$ for the interarea modes (frequencies $2.02,2.80$, and $4.06 \mathrm{rad} / \mathrm{s}$ ) are consistently greater than the P-Vr phase responses in Figs. 4 and 5 by 20-40 ${ }^{\circ}$. In other studies [11], the effect of interactions for interarea modes appears to degrade consistently the contribution to damping of PSS $j$ on machine $j$, while for local-area modes, interactions may enhance or degrade damping.

In conclusion, the implications of the above observations for the determination of the phase compensation required are

- Category 1: phase compensation can be provided either through a few residue angles (8) or from the P-Vr TF.

- Category 2: phase compensation is best provided by the $\mathrm{P}-\mathrm{Vr}$ TF because compensation based on the residue angles may be subject to significant variation about the value derived from the $\mathrm{P}-\mathrm{Vr}$ TF.

- Category 3: phase compensation based on residues for interarea modes is $\arg \left\{G_{R j}\left(\lambda_{h}\right)\right\}=-\beta_{j j}^{h}$ (from (8) and (15)) and is somewhat less than that suggested by the $\mathrm{P}-\mathrm{Vr}$ response since the latter does not account for interactions. In the P-Vr method, it may be judicious-after an appropriate analysis-to increase the amount of phase lead provided by the PSS TF by some $20-40^{\circ}$ at the lower interarea modal frequencies to counter what appears to be a consistent degradation in damping due to interactions [11].

From Figs. 4-6, it is clear that information for use in phase compensation based on residues is limited to a few reliable points over the possible range of modes of rotor oscillations. Moreover, there is no magnitude information provided, thus it may be difficult to synthesize a PSS TF.

On the other hand, the P-Vr frequency response provides reliable information on both magnitude and phase over the range of rotor modes; this simplifies considerably the synthesis of the PSS TF. In particular, the PSS gain $k_{j}$-by definition-is equivalent to the damping torque coefficient (as shown in Fig. 16 for the single machine case). The value of $k_{j}$ has practical significance: typically, a value of $k_{j}=20 \mathrm{p}$.u. on machine base is a moderate gain while $k_{j}>50$ p.u. tends to be a high value-that may result in significant swings in reactive power.

\section{B. Effect of Complex Participation Factors and Interactions}

In the tables, it is noted that the participation factors associated with the lower ranked residues are complex $p_{j h} \angle \phi_{j h}$. As an alternative approach, it is assumed that $\angle \phi_{j h}$ and $\arg \left\{r_{j j}^{h}\right\}$-and,

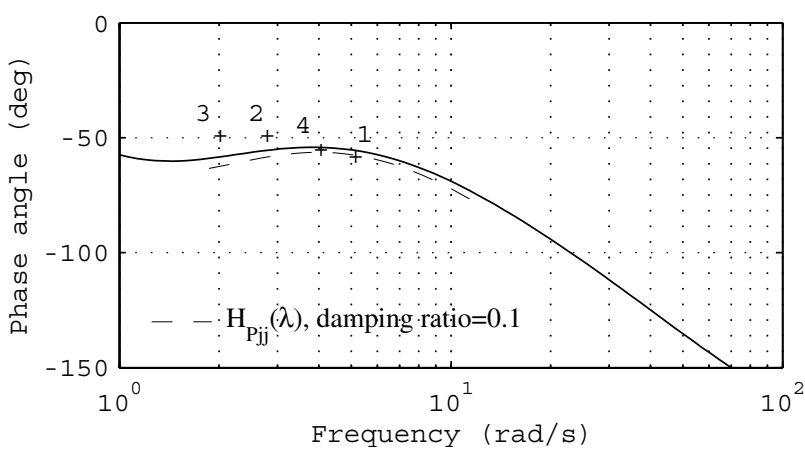

Fig. 7. Gen. 55: Angles $\theta(+)$ plotted on P-Vr phase response; ranked in order of magnitude of residues.

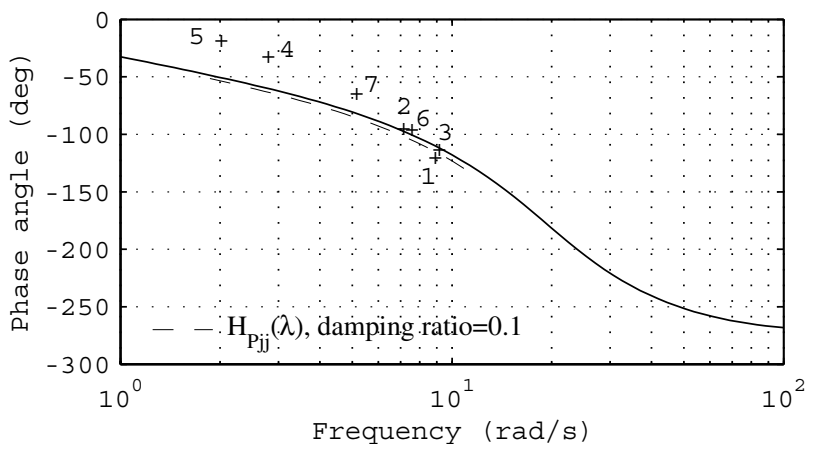

Fig. 8. Gen. 40: Angles $\theta(+)$ plotted on P-Vr phase response; ranked in order of magnitude of residues.

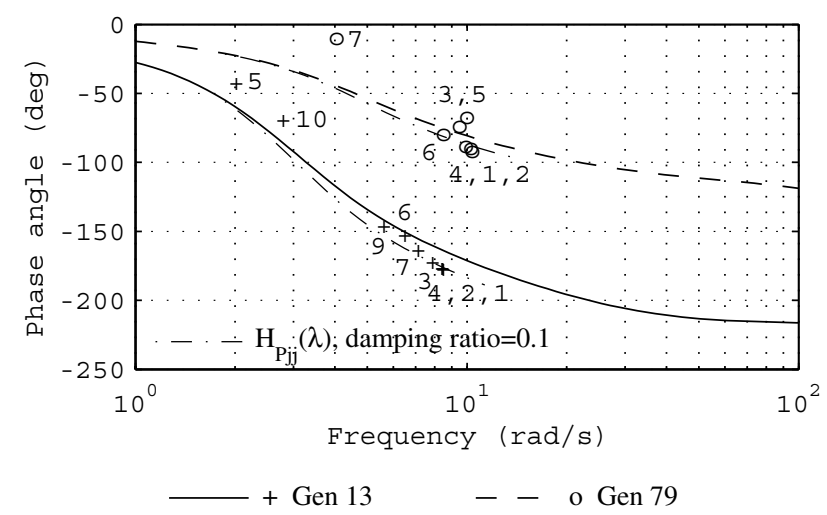

Fig. 9. Gen. 13 and 79: Angles $\theta$ plotted on P-Vr phase response; ranked in order of magnitude of residues.

hence, $\beta_{j j}^{h}$-are known. From (8), (13), and (15), we define the difference between these angles as

$$
\theta_{j h}=\beta_{j j}^{h}-\phi_{j h}=\arg \left\{H_{P j j}\left(\lambda_{h}\right)\right\}-\varepsilon_{j h} .
$$

Thus, if we account for complex participation factors, the difference between the angle point $\theta_{j h}$ and $H_{P j j}\left(\lambda_{h}\right)$ response at frequency $\lambda_{h}=\alpha_{h}+j \omega_{h}$ is due to interactions, manifested by the angle $\varepsilon_{j h}$. Note in the tables the modal damping ratios $\delta$ are generally less than 0.1 (i.e., $\delta \approx-\alpha / \omega$ ). As both $\beta_{j j}^{h}$ and $\phi_{i h}$ are given in Tables I-IV, we can plot $\theta_{j h}$ on the P-Vr phase responses together with $H_{P j j}(\alpha+j \omega)$ for $\delta=0.1$; the plots corresponding to Figs. 4-6 are shown in Figs. 7-9. The plots of $H_{P j j}(\lambda)$ differ from the $\mathrm{P}-\mathrm{Vr}$ responses by less than 5-10 $\mathrm{lag}$ 


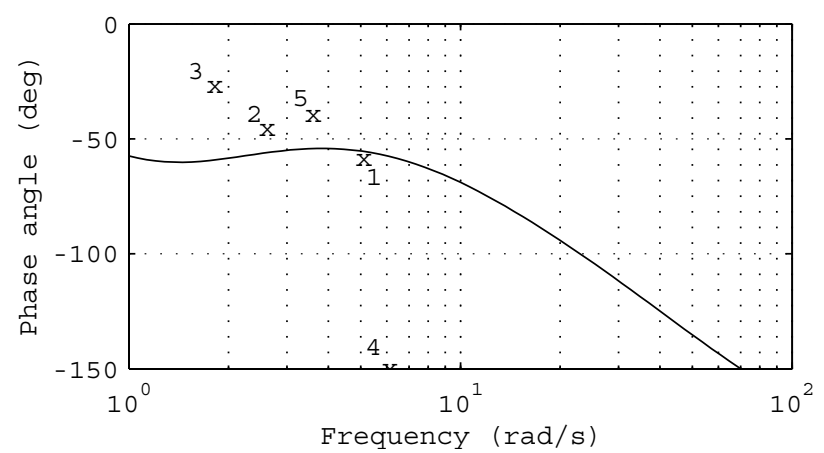

Fig. 10. Gen. 55. Angle $\beta(\mathrm{x})$ plotted on P-Vr phase response. PSSs off for station units; in service on other units in the system.

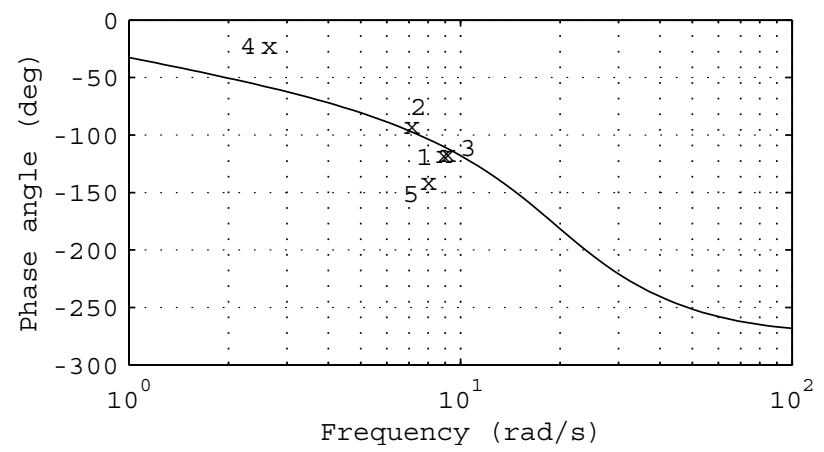

Fig. 11. Gen. 40. Angle $\beta(\mathrm{x})$ plotted on P-Vr phase response. PSSs off for station units; in service on other units in the system.

over the range of modal frequencies. Thus, for compensation, the use of the $\mathrm{P}-\mathrm{Vr}$ response introduces a small angle error.

It is noted that the angle points $\theta_{j h}$ agree more closely with the $\mathrm{P}-\mathrm{Vr} / H_{P j j}(\alpha+j \omega)$ responses than do the $\beta_{j j}^{h}$ points in the corresponding Figs. 4-6, isolating the effect of interactions. This is particularly the case for the intrastation and local-area modes because fewer machines participate in these modes and the effect of interactions is less marked. However, many machines participate in the interarea modes and the effect of interactions is significant; this is revealed in Figs. 7-9 by the offsets from the responses of $\mathrm{P}-\mathrm{Vr} \mathrm{TF}$ and $H_{P j j}(\alpha+j \omega), \delta=0.1$.

In conclusion, the latter analysis explains the reasons for the scatter of the angle points about the P-Vr plots in Figs. 4-6 and confirm the conclusions listed in categories 1-3 in part A. This is further discussed in Appendix C.

\section{Evaluating Residues With PSSs in Service}

In part A, the residues are evaluated with all PSSs out of service for determining the required PSS compensation. A practical question arises: when PSSs are in service, how does phase compensation based on residues and the P-Vr TF compare? Except for the machine of interest and possibly other units in the same station, these calculations are now repeated with PSSs on all other units in the system in service.

To provide some slightly differing scenarios, the calculation for units 55, 40, and 79, respectively, in Figs. 10-12, the PSS of the second of the two units is off, however, for unit 13 in Fig. 12, the PSSs on the other units in the station are in service.

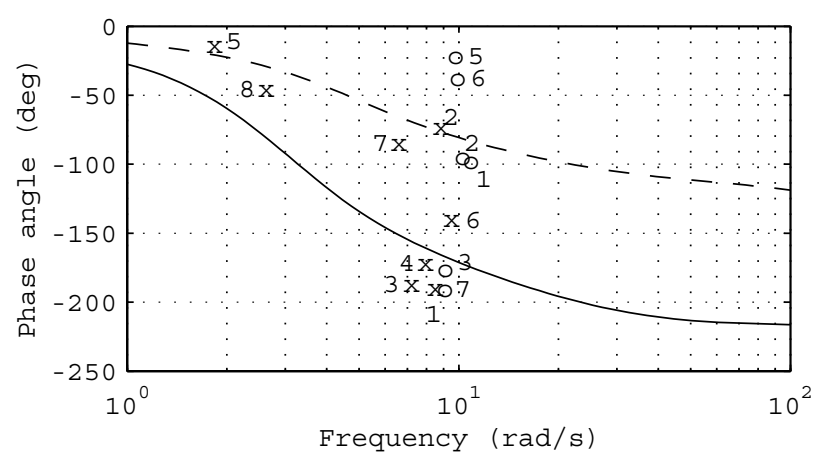

- $\mathrm{x}$ Gen $13 \quad-\quad-$ o Gen 79

Fig. 12. Gen. 13 and 79. Angle $\beta$ plotted on P-Vr phase response. PSSs on other units in the station and the system in service.

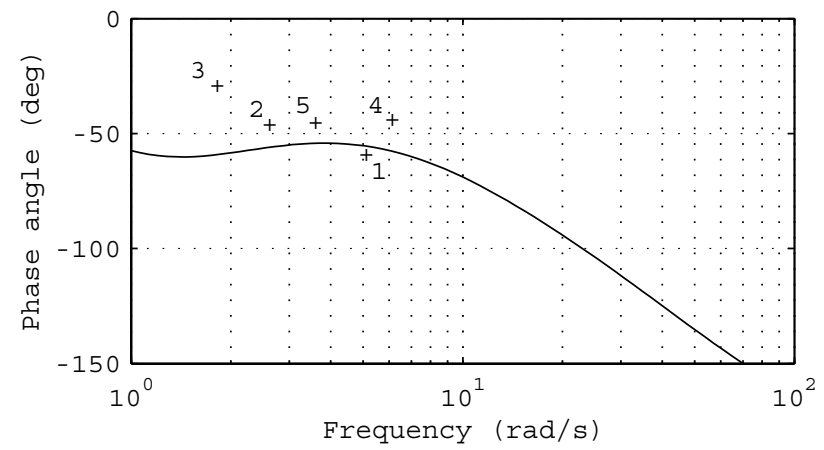

Fig. 13. Gen. 55: Angles $\theta(+)$ plotted on P-Vr phase response; PSSs off for station units, in service on other units in the system.

To facilitate the comparison with the residues calculated with all PSSs off, the following comments are made:

- As expected, the nature and value of the modes are changed from the PSSs-off condition. The scatter of the angle points $\beta_{j j}^{h}$ from the $\mathrm{P}-\mathrm{Vr}$ response is similar (Gen. 40 ), or increased (particularly for local-area modes of Gens. 55, 13, and 79).

- As for the PSSs-off condition, the points for the interarea modes are consistently greater than the P-Vr phase responses.

It is of interest to assess again the effects of both complex participation factors and interactions on the residues. For the four generators, the angle points $\theta_{j h}$ given by (16) are calculated from Tables V-VIII and plotted in Figs. 13-15.

An examination of Figs. 13-15 and Figs. 10-12 yields a set of observations similar to those in part B for Figs. 7-9 and Figs. 4-6. Thus, in the analysis of residues, it may make little difference whether the studies are conducted with the PSSs on other units in- or out-of-service.

\section{CONCLUSION}

If there are lightly damped modes in the GEP TF $V_{\mathrm{ti}}(j \omega) / V_{\mathrm{ri}}(j \omega)$ of machine $i$ in a multimachine system, resonances may distort the phase response. Based on a linearized model of the system it is found that if the shaft dynamics of all machines are disabled, not only is a "smoothed" representation of phase response of the GEP TF derived but it 


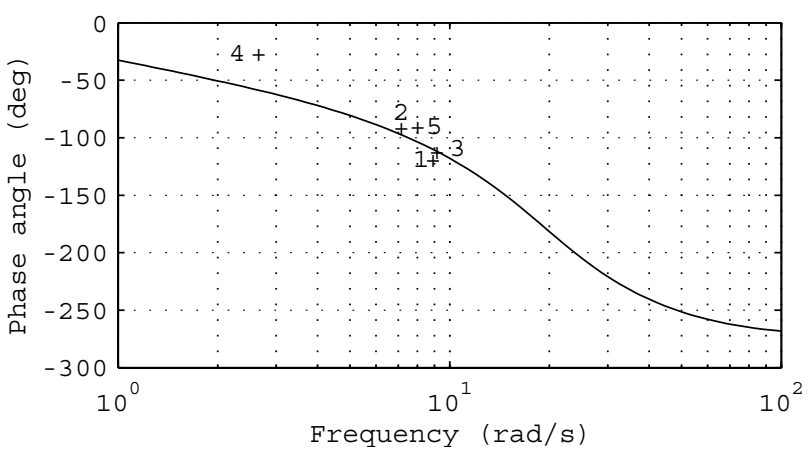

Fig. 14. Gen. 40. Angle $\theta(+)$ plotted on P-Vr phase response. PSSs off for station units; in service on other units in the system.

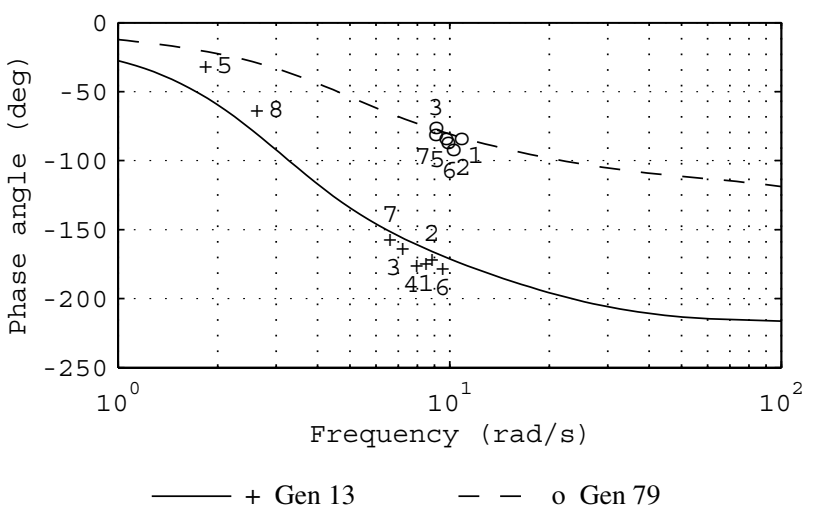

Fig. 15. Gen. 13 and 79. Angle $\theta$ plotted on P-Vr phase response. PSSs on other units in the station and the system in service.

TABLE $\mathrm{V}$

GENERATOR 55 (PSSS OFF FOR BOTH UNITS IN THE STATION) RESIDUES OF ROTOR MODES IN TF $\Delta \omega / \Delta V_{r}$ (SEE FIG. 10)

\begin{tabular}{l|l|l|l|l}
\hline $\begin{array}{l}\text { Rank- } \\
\text { ing }\end{array}$ & $\begin{array}{c}\text { Rotor Mode } \lambda_{\mathrm{h}} \\
\& \text { Type }\end{array}$ & $\begin{array}{c}\text { PF (units) } \\
/ \text { Ranking }\end{array}$ & $\begin{array}{c}\text { Residue } \\
\text { (units) }\end{array}$ & $\angle \beta_{j j}^{h^{\circ}}$ \\
\hline 1 & $-0.54+\mathrm{j} 5.13$ LA & $468 \angle 0^{\circ} / 1$ & $12 \angle 122^{\circ}$ & $-58^{\circ}$ \\
\hline 2 & $-0.32+\mathrm{j} 2.62$ IA & $29 \angle 0^{\circ} / 1$ & $0.47 \angle 135^{\circ}$ & $-45^{\circ}$ \\
\hline 3 & $-0.26+\mathrm{j} 1.82$ IA & $13 \angle 2^{\circ} / 39$ & $0.21 \angle 154^{\circ}$ & $-26^{\circ}$ \\
\hline 4 & $-1.67+\mathrm{j} 6.14$ LA & $8 \angle-109^{\circ} />40$ & $0.15 \angle 28^{\circ}$ & $-152^{\circ}$ \\
\hline 5 & $-0.61+\mathrm{j} 3.61$ IA & $6 \angle 5^{\circ} />40$ & $0.11 \angle 141^{\circ}$ & $-39^{\circ}$ \\
\hline
\end{tabular}

1 unit $=10^{-3}$. See Table I for definition of terms.

also corresponds closely with phase response of the P-Vr TF. Thus, like the P-Vr TF, the phase information from the GEP TF (shaft dynamics disabled) can provide the basis for the design of a robust PSS, however, the magnitude response of the latter GEP TF yields no useful information.

While residues provide the ideal phase compensation for a given mode and operating condition, they are subject to an unknown variability in both the phase of participation factors and effects of interactions over a range of operating conditions. It is shown that for the purposes of phase compensation, the method of residues yields only a limited number of residue angles (typically 1 to 4) that agree closely with the $\mathrm{P}-\mathrm{Vr}$ phase response and can be used with confidence for design purposes. This is the case for a machine $i$ whose speed state participates significantly in the relevant mode and for which the participation factor is real-or close to real. However, for modes in which the speed state of a machine participates moderately or weakly,
TABLE VI

GENERATOR 40 (PSSS OFF FOR BOTH UNITS IN THE STATION) RESIDUES OF ROTOR MOdES IN TF $\Delta \omega / \Delta V_{r e f}$ (SEE FIG. 11)

\begin{tabular}{l|l|l|l|l}
\hline $\begin{array}{l}\text { Rank- } \\
\text { ing }\end{array}$ & $\begin{array}{c}\text { Rotor Mode } \\
\& \text { Type }\end{array}$ & $\begin{array}{c}\text { PF (units) } \\
/ \text { Ranking }\end{array}$ & $\begin{array}{c}\text { Residue } \\
\text { (units) }\end{array}$ & $\angle \beta_{j j}^{h}$ \\
\hline 1 & $-0.64+\mathrm{j} 8.93$ IS & $260 \angle 1^{\circ} / 1$ & $66 \angle 63^{\circ}$ & $-117^{\circ}$ \\
\hline 2 & $-0.25+\mathrm{j} 7.15 \mathrm{LA}$ & $140 \angle 1^{\circ} / 1$ & $38 \angle 91^{\circ}$ & $-89^{\circ}$ \\
\hline 3 & $-0.88+\mathrm{j} 9.19 \mathrm{LA}$ & $65 \angle-5^{\circ} / 9$ & $18 \angle 64^{\circ}$ & $-116^{\circ}$ \\
\hline 4 & $-0.28+\mathrm{j} 2.66 \mathrm{IA}$ & $20 \angle 3^{\circ} / 19$ & $4 \angle 158^{\circ}$ & $-22^{\circ}$ \\
\hline 5 & $-2.49+\mathrm{j} 8.02 \mathrm{LA}$ & $5 \angle-51^{\circ} />40$ & $2 \angle 40^{\circ}$ & $-140^{\circ}$ \\
\hline
\end{tabular}

1 unit $=10^{-3}$. See Table I for definition of terms.

TABLE VII

GENERATOR 13 (PSSS ON FOR OTHER UNITS IN THE STATION) RESIDUES OF ROTOR MODES IN TF $\Delta \omega / \Delta V_{\text {ref }}$ (SEE FIG. 12)

\begin{tabular}{l|l|l|l|l}
\hline $\begin{array}{l}\text { Rank- } \\
\text { ing }\end{array}$ & $\begin{array}{c}\text { Rotor Mode } \\
\text { \& Type }\end{array}$ & $\begin{array}{c}\text { PF (units) / } \\
\text { Ranking \# }\end{array}$ & $\begin{array}{c}\text { Residue } \\
\text { (units) }\end{array}$ & $\angle \beta_{j j}^{h^{\circ}}$ \\
\hline 1 & $-0.63+\mathrm{j} 8.49$ LA & $402 \angle-16^{\circ} / 1$ & $30 \angle-9^{\circ}$ & $-189^{\circ}$ \\
\hline 2 & $-0.59+\mathrm{j} 8.86$ LA & $108 \angle 98^{\circ} / 5$ & $7 \angle 108^{\circ}$ & $-72^{\circ}$ \\
\hline 3 & $-0.66+\mathrm{j} 7.23$ LA & $39 \angle-24^{\circ} / 11$ & $4 \angle-6^{\circ}$ & $-186^{\circ}$ \\
\hline 4 & $-1.00+\mathrm{j} 7.96$ LA & $37 \angle 5^{\circ} / 6$ & $3 \angle 11^{\circ}$ & $-169^{\circ}$ \\
\hline 5 & $-0.24+\mathrm{j} 1.84$ IA & $17 \angle 17^{\circ} / 16$ & $2 \angle 167^{\circ}$ & $-13^{\circ}$ \\
\hline 6 & $-0.73+\mathrm{j} 9.53$ LA & $28 \angle 37^{\circ} / 19$ & $2 \angle 41^{\circ}$ & $-139^{\circ}$ \\
\hline 7 & $-0.54+\mathrm{j} 6.62$ LA & $16 \angle 71^{\circ} / 18$ & $2 \angle 96^{\circ}$ & $-84^{\circ}$ \\
\hline 8 & $-0.30+\mathrm{j} 2.63$ IA & $7 \angle 17^{\circ} />40$ & $1 \angle 135^{\circ}$ & $-45^{\circ}$ \\
\hline
\end{tabular}

1 unit $=10^{-3}$. See Table I for definition of terms.

TABLE VIII

GENERATOR 79 (PSSS OFF FOR BOTH UNITS IN THE STATION) RESIDUES OF ROTOR MODES IN TF $\Delta \omega / \Delta V_{\text {ref }}$ (SEE FIG. 12)

\begin{tabular}{l|l|l|l|l}
\hline $\begin{array}{l}\text { Rank- } \\
\text { ing }\end{array}$ & $\begin{array}{c}\text { Rotor Mode } \\
\text { \& Type }\end{array}$ & $\begin{array}{c}\text { PF (units) } \\
/ \text { Ranking }\end{array}$ & $\begin{array}{c}\text { Residue } \\
\text { (units) }\end{array}$ & $\angle \beta_{j j}^{h^{\circ}}$ \\
\hline 1 & $-1.13+\mathrm{j} 10.9$ LA & $230 \angle-15^{\circ} / 1$ & $111 \angle 83^{\circ}$ & $-97^{\circ}$ \\
\hline 2 & $-0.86+\mathrm{j} 10.3$ LA & $223 \angle-4^{\circ} / 3$ & $100 \angle 86^{\circ}$ & $-94^{\circ}$ \\
\hline 3 & $-1.44+\mathrm{j} 9.13$ LA & $74 \angle-101^{\circ} / 9$ & $44 \angle 5^{\circ}$ & $-175^{\circ}$ \\
\hline 4 & $-1.34+\mathrm{j} 9.03$ LA & $59 \angle 105^{\circ} / 25$ & $34 \angle-147^{\circ}$ & $-327^{\circ} \#$ \\
\hline 5 & $-1.36+\mathrm{j} 9.79$ LA & $48 \angle 61^{\circ} / 7$ & $25 \angle 159^{\circ}$ & $-21^{\circ}$ \\
\hline 6 & $-0.82+\mathrm{j} 9.93$ LA & $44 \angle 48^{\circ} / 3$ & $21 \angle 147^{\circ}$ & $-37^{\circ}$ \\
\hline 7 & $-2.69+\mathrm{j} 9.11$ LA & $18 \angle-111^{\circ} / 40$ & $19 \angle-10^{\circ}$ & $-190^{\circ}$ \\
\hline
\end{tabular}

1 unit $=10^{-3}$. See Table I for definition of terms. \# indicates value not plotted on figure.

the phase of the participation factor and the effect of interactions due to other machines, particularly for local-area and intrastation modes, is shown to produce a scatter of angles $\beta_{j j}^{h}$ (= residue angle- $180^{\circ}$ ) about its continuous $\mathrm{P}-\mathrm{Vr}$ phase response; the $\mathrm{P}-\mathrm{Vr}$ response thus provides a good estimate of the residue angles through $\beta_{j j}^{h}$. In the case of interarea modes, the effects of interactions appear such as to provide a consistent offset in the angle $\beta_{j j}^{h}$ from the $\mathrm{P}-\mathrm{Vr}$ phase response. Based on the $\mathrm{P}-\mathrm{Vr}$ phase response, it may be judicious to increase the phase lead provided by the PSS TF by $20-40^{\circ}$ at the lower interarea modal frequencies to counter the degradation in damping.

Of the three methods, which are complementary, the $\mathrm{P}-\mathrm{Vr}$ frequency response provides continuous, consistent information for both phase and magnitude over the range of rotor modal frequencies and operating conditions; this simplifies considerably the synthesis of the PSS TF and its tuning. In particular, the PSS gain $k_{j}$-by its definition a damping torque coefficient-is a meaningful quantity; for example, $k_{j}$ of 20 p.u. on machine base is a moderate gain value. Moreover, using the associated stabilizer damping contribution diagrams, a practical procedure 
can be implemented for the coordination of PSSs to satisfy the specifications for modal damping [11]-[13].

\section{APPENDIX A}

\section{PSS DESIGN BASED ON THE P-Vr METHOD}

The $\mathrm{P}-\mathrm{Vr} \mathrm{TF}$ for generator $i$ is the TF from the AVR voltage reference input $V r$ on generator $i$ to the torque of electromagnetic origin $(\approx$ power output, $P)$ on generator $i$, calculated with the shaft dynamics of all machines disabled [4], [5].

The stabilizer TFs are of the form $k_{i} G_{i}(s)$. Including wash-out and low-pass filters, $G_{i}(s)$ takes the form

$$
K_{0} \frac{\left(s+\cdots+b_{m} s^{m}\right)}{\left(1+\cdots+a_{n} s^{m}\right)}, m \leq n,
$$

and is designed to achieve a left-shift in the relevant modes of rotor oscillation. The gain $k_{i}$ (on machine base), which is referred to as the "gain" of the PSS, determines the extent of the left-shift. The aim of the design procedure is to introduce on the generator shaft a damping torque (a torque proportional to machine speed); this causes the modes of rotor oscillation to be shifted to the left in the $s$-plane. The ideal TF between speed $\Delta \omega_{i}(s)$ and electrical torque perturbations $\Delta P_{i i}(s)$ over the range of complex frequencies of the rotor modes should be $D_{e i}=\Delta P_{i i}(s) / \Delta \omega_{i}(s)$, where $D_{e i}$ is a damping torque coefficient (e.g., as in Fig. 16) and is a real number (per unit on machine base). Let $H_{P i i}(s)$ be the P-Vr TF. The TF $G_{i}(s)$ compensates in magnitude as well as phase for the TF $H_{P i i}(s)$ of machine $i$. Assuming rotor speed is used as the input signal to the PSS, with output $V_{s i}$, the expression for $D_{e i}$ can be written

$$
\begin{aligned}
D_{e i} & =\left(\frac{\Delta P_{i i}}{\Delta V_{s i}}\right) \cdot\left(\frac{\Delta V_{s i}}{\Delta \omega_{i}}\right)=H_{P i i}(s) \cdot\left[k_{i} G_{i}(s)\right], \\
\text { or }\left[k_{i} G_{i}(s)\right] & =\frac{D_{e i}}{H_{P i i}(s)} .
\end{aligned}
$$

Hence, ideally $k_{i}=D_{e i}$ and $G_{i}(s)=1 / H_{P i i}(s)$. The gain $k_{i}$ of the PSS can thus also be considered to be a damping torque coefficient. The practical, proper TF for the $i$-th PSS is

$$
\left[k_{i} G_{i}(s)\right]=k_{i}\left\{\frac{1}{P V R_{i}(s)}\right\} \times\{\text { filter TFs }\},
$$

where $P V R_{i}(s)$ is the synthesized form of $H_{P i i}(s)$. As most rotor modes are relatively lightly damped, $s$ can be replaced by $j \omega$ and conventional frequency response methods can be employed in the design procedure. The aim of a design is to ensure that over the range of frequencies of rotor oscillations, the magnitude response of (17) is flat with zero or slightly lagging phase shift. Because of the more-or-less invariant nature of the $\mathrm{TF} H_{P i i}(s)$ over a wide range of operating conditions, fixed-parameter PSSs tend to be robust [5].

\section{APPENDIX B}

\section{Single-MACHINE MODEL}

A single-machine system is shown in Fig. 16[1]. With the shaft dynamics disabled (i.e., $\Delta \delta=0$ ), we can evaluate the TFs

$$
\frac{\Delta T_{e}}{\Delta V_{r}}=\frac{K_{2} K_{3}}{1+s K_{3} T_{d 0}^{\prime}}, \quad \frac{\Delta V_{t}}{\Delta V_{r}}=\frac{K_{6} K_{3}}{1+s K_{3} T_{d 0}^{\prime}} .
$$

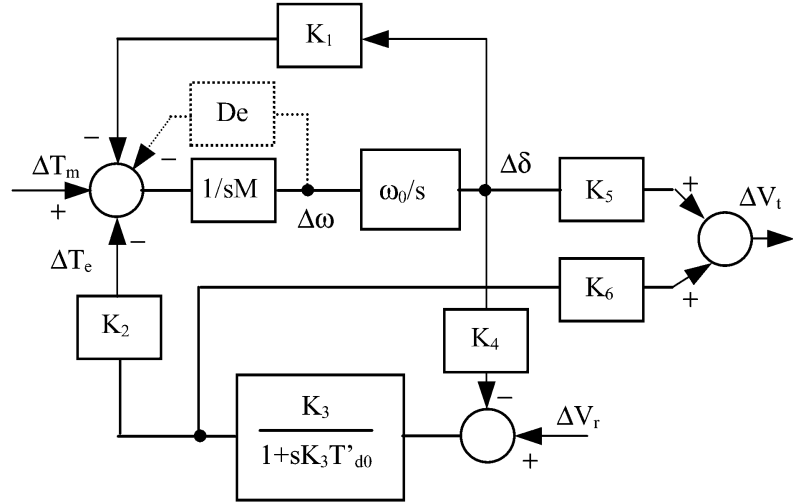

Fig. 16. Model of a single-machine infinite bus system. An ideal speed-PSS is represented by gain $k=D_{e}$, the damping torque coefficient.

These TFs are the P-Vr and the GEPSDD TFs, respectively, and are related by the factor $K_{2} / K_{6}$ for the case of this simple model. The magnitude plots in the associated frequency responses will thus differ by a constant amount, however, the phase responses will be identical.

Note in Fig. 16 an equivalent speed-PSS can be idealized by the PSS gain $k=D_{e}$, a damping torque coefficient.

\section{APPENDIX C \\ EFFECTS OF INTERACTIONS ON RESIDUES}

According to (5) for the residue, the effects of interactions are small (e.g., if the products $p_{* h} H_{P * j}$. in the summation term are each small or negligible compared to that for the generator of concern $j$. Note that the ratio of the right speed eigenvector elements $u_{j h} / u_{i h}$ is the "mode shape" of generator $j$ relative to that of $i$. Hence, (5) becomes

$$
r_{j j}^{h} \approx-\left(\frac{p_{j h}}{M_{j}}\right) H_{P j j}\left(\lambda_{h}\right) .
$$

In this case, if the participation factor $p_{j h}$ of the speed state of machine $j$ in mode $h$ is real, the angle point $\beta_{j j}^{h}$ associated with $r_{j j}^{h}$ will agree closely with the $\mathrm{P}-\mathrm{Vr}$ phase response at frequency $\omega=\operatorname{Im}\left(\lambda_{h}\right)$. This applies to the category 1 residues for generators 55 and 40. For example, from Table II, row 1 for the intrastation mode of gen. 40 , the self and interaction terms are $6.2 e-02 \angle 67^{\circ}$ and $6.1 e-03 \angle 7^{\circ}$, respectively; the residue is thus dominated by the self term. However, if the participation factor $p_{j h}$ is complex, the residue angle will be augmented by that of the participation factor; this is primarily the case in row 2 of Table III for gen. 13 for a local-area mode.

However, if the product term $p_{j h} \cdot H_{P j j}$ for generator $j$ is comparable to similar quantities in the interaction terms in (5), $\arg \left\{r_{j j}^{h}\right\}$ may be affected markedly by the interaction term. In this case, a category 2 residue, the angle point $\beta_{j j}^{h}$ will deviate from the $\mathrm{P}-\mathrm{Vr}$ phase response at frequency $\omega=\operatorname{Im}\left(\lambda_{h}\right)$-even if $p_{j h}$ is real. This is often the case for interarea modes in which the interaction term is comparable with, and in near phase opposition to, the self term (e.g., $5.2 e-03 \angle-60^{\circ}$ and $6.5 e-03 \angle 131^{\circ}$ ), respectively, for row 5 of Table II. Note, using (10), the phase of the interactions factor $E_{j h} \angle \varepsilon_{j h}=0.27 \angle 34^{\circ}$ is consistent with the offset of $\sim 34^{\circ}$ from the P-Vr response in Fig. 8. 


\section{REFERENCES}

[1] F. P. de Mello and C. Concordia, "Concepts of synchronous machine stability as affected by excitation control," IEEE Trans. Power App. Syst., vol. PAS-88, pp. 316-329, Apr. 1969.

[2] E. V. Larsen and D. A. Swann, "Applying power system stabilizers: Part I - III," IEEE Trans. Power App. Syst., vol. PAS-100, pp. 3017-3046, June 1981.

[3] P. Kundur, M. Klein, G. J. Rogers, and M. S. Zywno, "Application of power system stabilizers for enhancement of overall stability," IEEE Trans. Power Syst., vol. 4, pp. 614-626, May 1989.

[4] F. P. de Mello, J. S. Czuba, P. A. Rushe, and J. R. Willis, "Developments in application of stabilizing measures through excitation control," in CIGRE, 1986, 38-05.

[5] M. J. Gibbard, "Coordinated design of multi-machine power system stabilisers based on damping torque concepts," Proc. Inst. Elect. Eng. C, vol. 135, pp. 276-284, July 1988.

[6] _ , "Robust design of fixed-parameter power system stabilisers over a wide range of operating conditions," IEEE Trans. Power Syst., vol. 6, pp. 794-800, May 1991.

[7] P. Pourbeik, "Design and coordination of stabilizers for generators and facts devices in multi-machine power systems," Ph.D. dissertation, Univ. Adelaide, Dept. of Electrical and Electronic Engineering, 1997.

[8] D. M. Lam and H. Yee, "A study of frequency responses of generator electrical torques for power system stabilizer design," IEEE Trans. Power Syst., vol. 3, pp. 1136-1142, Aug. 1998.

[9] P. Pourbeik, M. J. Gibbard, and D. J. Vowles, "Proof of the equivalence of residues and induced torque coefficients for use in the calculation of eigenvalue shifts," IEEE Power Eng. Rev., Power Eng. Lett., vol. 22, no. 1, pp. 58-60, Jan. 2002.

[10] N. Martins and L. T. G. Lima, "Determination of suitable locations for power system stabilizers and static var compensators for damping electromechanical oscillations in large scale power systems," IEEE Trans. Power Syst., vol. 5, pp. 1455-1469, Nov. 1990.

[11] M. J. Gibbard, D. J. Vowles, and P. Pourbeik, "Interactions between, and effectiveness of, power system stabilizers and FACTS stabilizers in multi-machine systems," IEEE Trans. Power Syst., vol. 15, pp. 748-755, May 2000.
[12] "Impact of Interactions Among Power System Controllers," CIGRE Publication, Task Force-02-16, Tech. Brochure 161, 2000.

[13] P. Pourbeik and M. J. Gibbard, "Simultaneous coordination of powersystem stabilizers and facts device stabilizers in a multi-machine power system for enhancing dynamic performance," IEEE Trans. Power Syst., vol. 13, pp. 473-479, May 1998

Michael Gibbard (S'67-M'69-SM'01-F'03) received the B.Sc. (Eng.) degree from the University of the Witwatersrand, Johannesburg, South Africa, in 1957, the Certificate in Business Administration from the London School of Economics, London. U.K., in 1961, and the Ph.D. degree from Queen's University, Kingston, ON, Canada, in 1968.

Currently, he is an Honorary Visiting Research Fellow at The University of Adelaide, Adelaide, South Australia, where he has been since 1970. From 1958 to 1960, he was with Associated Electrical Industries, Rugby, U.K. He joined the Snowy Mountains Hydro-Electric Authority, Cooma, NSW, Australia, from 1961 to 1965 . In 1969-70, he was with Imperial Chemical Industries, Melbourne, Australia.

David Vowles (M'96) received the B.Sc. and B.E. (hons.) degrees in electrical and electronic engineering from The University of Adelaide, Adelaide, South Australia, in 1983 and 1984, respectively.

Currently, he is a Research Engineer with The University of Adelaide. He was with the Hydro-Electric Commission of Tasmania, Hobart, Australia, from 1984 to 1987 and with Portland Smelter Services, Portland, Victoria, Australia, from 1987 to 1989 . 